\title{
Role of Inorganic Polyphosphate in the Energy Metabolism of Ticks
}

\author{
Eldo Campos ${ }^{1,4}$, Arnoldo R. Façanha²,4, \\ Jorge Moraes 1,4 and Carlos Logullo 3,4 \\ ${ }^{1}$ Universidade Federal do Rio de Janeiro - Macaé \\ 2Universidade Estadual do Norte Fluminense \\ ${ }^{3}$ Universidade Estadual do Norte Fluminense \\ ${ }^{4}$ Instituto Nacional de Ciência e Tecnologia - Entomologia Molecular \\ Brazil
}

\section{Introduction}

Inorganic polyphosphates are long chains of a few to several hundred phosphate residues linked by phosphoanhydride bonds (Figure 1). Polyphosphates have been found in all cell types examined to date and have been demonstrated to play diverse roles depending on the cell type and circumstances (Kornberg et al., 1999; Kulaev \& Kulakovskaya, 2000). The biological roles played by polyphosphates have been most extensively studied in prokaryotes and unicellular eukaryotes, where they have been shown to regulate many biochemical processes including the metabolism and transport of inorganic phosphate, cation sequestration and storage (Kornberg et al., 1999), and membrane channel formation (Reusch, 1989; Jones et al., 2003), and they have also been found to be involved in cell envelope formation and bacterial pathogenesis (Rashid et al., 2000; Kim et al., 2002), the regulation of gene and enzyme activities (McInerney et al., 2006), the activation of Lon proteases (Kuroda et al., 2001), and KcsA channel regulation (Negoda et al., 2009).

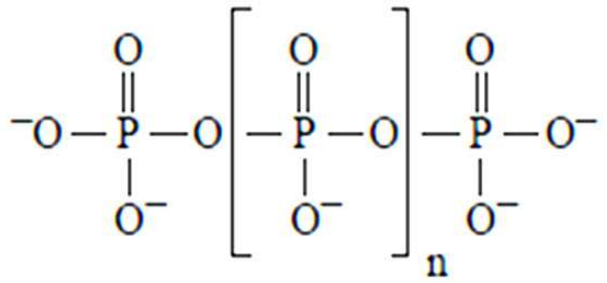

Fig. 1. Inorganic Polyphosphate

Conversely, polyphosphate functions have not been extensively investigated in higher eukaryotes; however, there is a good deal of interest in polyphosphates in mitochondria regarding two circumstances: polyphosphate as a macroenergetic compound with the same energy hydrolysis of the phosphoanhydride bond as an ATP and, according to the endosymbiotic theory, mitochondria originated from ancient prokaryotic cells (Clements et 
al., 2009; Kulakovskaya et al., 2010), thus, it would be intriguing to discover whether or not mitochondria have preserved polyphosphate functions such as the regulation of energy metabolism and the participation in transport channel formation.

\section{Polyphosphate mobilization during Rhipicephalus (Boophilus) microplus embryogenesis}

The tick Rhipicephalus microplus is a one-host tick that causes major losses to bovine herds, especially in tropical regions. In this scenario, major efforts have been made to develop immunoprophylatic tick control tools (Guerrero et al., 2006). Ticks are also vectors of parasites that cause hemoparasitic diseases, which are endemic in many cattle production areas (Sonenshine et al., 2006). Rhipicephalus microplus only has one host throughout all three life stages, usually a bovine animal, and a long feeding period (approximately 21 days). The adult female, after becoming completely engorged, drops off of the host and initiates oviposition approximately three days later. Being an oviparous creature, embryogenesis occurs in the absence of exogenous nutrients, and maternal nutrients are packaged in oocytes and mostly stored as yolk granules. Hatching occurs around 21 days after oviposition, and the emerging larvae can survive for several weeks before finding a host, using the remaining yolk as the only source of energy (Fagotto, 1990).

Early R. microplus embryonic stages are similar to those of $D$. melanogaster and mosquitoes (Bate \& Arias, 1991; Monnerat et al., 2002). Tick embryogenesis is characterized by the formation of a non-cellular syncytium up to day 4 (Campos et al., 2006). After this, the embryo becomes a multicellular organism and starts organogenesis (Campos et al., 2006).

The function of polyphosphate as a phosphate reserve is well known in prokaryotes and also in eukaryote microorganisms (Kulaev \& Vagabov, 1983; Kornberg, 1995; Kulaev, 2004). The cells of higher eukaryotes also carry polyphosphate, but in smaller amounts than found in microorganisms. Therefore, as well as being a source of phosphate, these biopolymers probably participate in regulatory processes (Kornberg et al., 1999). Total polyphosphate levels were quantified throughout $R$. microplus embryogenesis and the levels were found to be higher during embryo cellularization and segmentation, from the fifth to the seventh day of development, and declined after that until a plateau was reached. The free phosphate content rapidly decreased during syncytial blastoderm formation on the third day of development, and remained low until the twelfth day of embryogenesis, when it rapidly increased thereafter (Figure 2A). Exopolyphosphatase splits phosphate off from the end of a polyphosphate chain and represents one of the main enzyme types responsible for polyphosphate hydrolysis (Kulaev et al., 2004). The activity of exopolyphosphatase was analyzed during embryogenesis and its activity was in agreement with total polyphosphate mobilization (Figure 2B).

It is interesting to note that in R. microplus the decline in total polyphosphate content after the seventh day of embryogenesis did not reflect the increase in the free phosphate content, since this only occurs after the twelfth day, suggesting that polyphosphate also plays roles other than being a phosphate reserve for embryo development. In this case, an alternative source of phosphate could be derived from the dephosphorylation of vitellin, a major yolk protein that is gradually dephosphorylated throughout embryogenesis (Silveira et al., 2006). This source could mainly be used until segmentation of the embryo, on the seventh day of development, because there is no total polyphosphate mobilization during this period. 

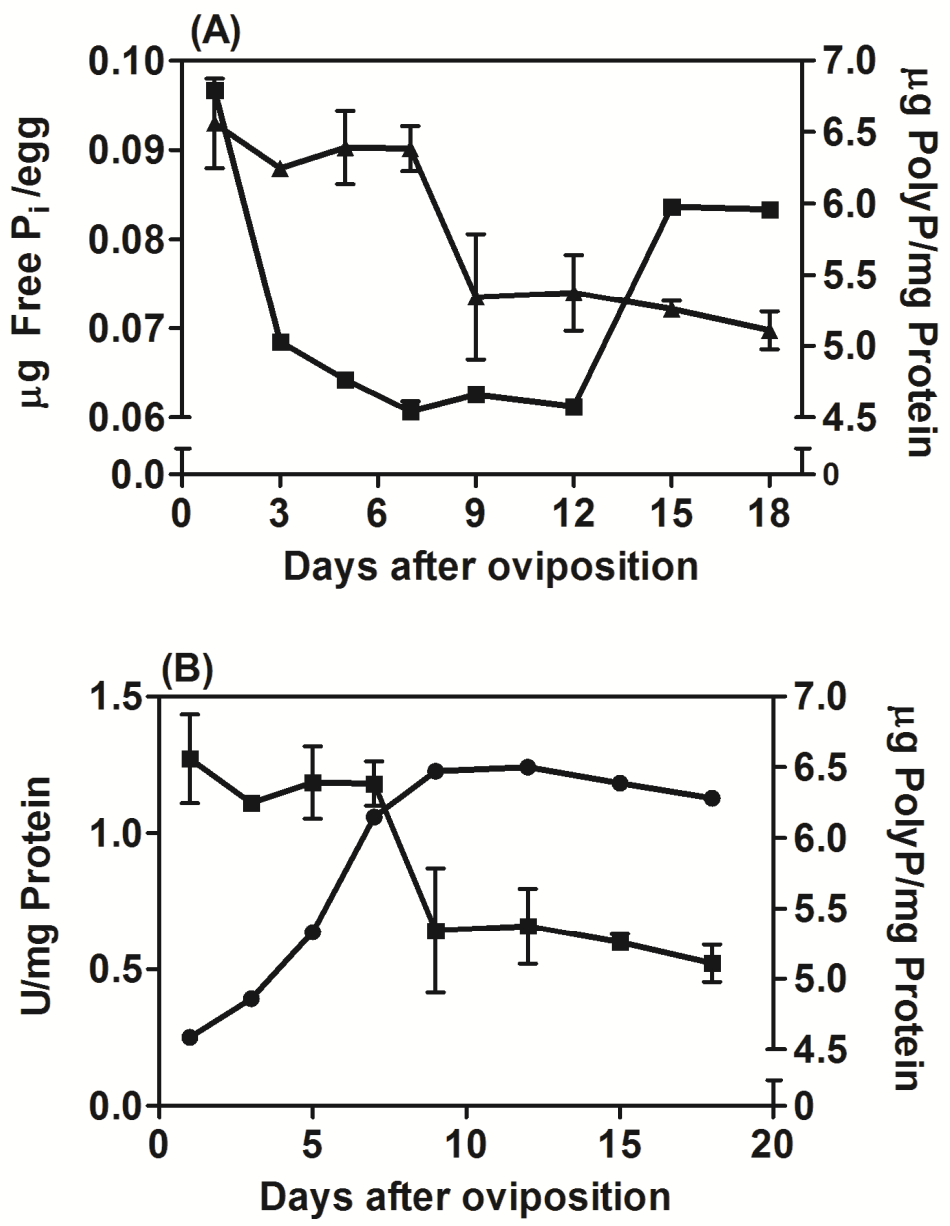

Fig. 2. Characterization of the total polyphosphate content during $R$. microplus embryogenesis. A) Total polyphosphate $(\boldsymbol{\Delta})$ was extracted and quantified and free phosphate (-) was quantified in an egg homogenate on different days after oviposition. B) Total polyphosphate $(\boldsymbol{\Delta})$ was extracted and quantified and exopolyphosphatase activity $(\bullet)$ was analyzed in an egg homogenate on different days after oviposition. Activity is expressed as units per milligram of total protein. The results represent the mean \pm SD of three independent experiments, in triplicate.

Quantification of the major energy sources in the egg over the course of $R$. microplus embryogenesis suggests that lipids and carbohydrates are the main energy source used during early development of the embryo. The total lipid contents remained stable until the fifth day, dropped on the seventh day, and remained roughly unchanged until hatching (Figure 3A). The total sugar contents exhibited a similar pattern, although slightly delayed: the values remained stable until the seventh day, dropped on the ninth day and remained 
constant until hatching (Figure 3B). This pattern suggests the utilization of lipids during the course of cellularization, a maternally driven process (Bate \& Arias, 1993). On the other hand, carbohydrates would be the major energy source for the quick segmentation of the embryo, of zygotic nature (Nusslein-Volhard \& Roth, 1989; Bate \& Arias, 1993).
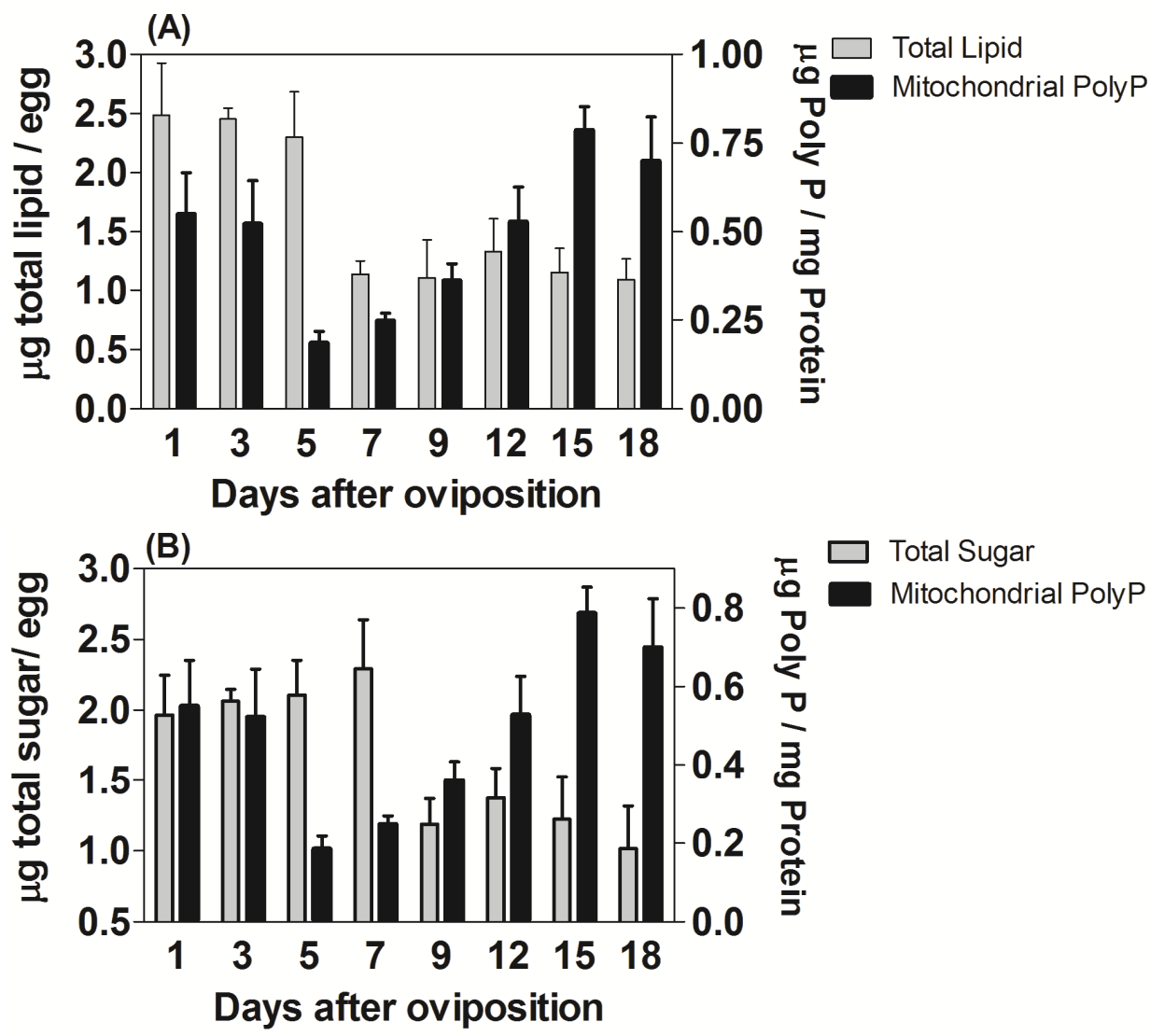

Fig. 3. Consumption of energetic sources. The major egg storage components of $R$. microplus were quantified on different days after oviposition. A) Lipid quantification, determined via the gravimetric method (Bligh \& Dyer, 1959); B) total sugar concentration, measured using the method of Dubois (Dubois et al., 1956). The results represent the mean \pm SD of three independent experiments, in triplicate.

Interestingly, mitochondrial polyphosphate utilization occurred during blastoderm formation and segmentation of the embryo, between the fifth and seventh days of development, and higher total polyphosphate utilization occurred after blastoderm formation and segmentation of the embryo, after the seventh day of development (Figure 4). Thus, mitochondrial polyphosphate levels seemed to correlate with the energy demand of the embryo during these developmental stages, during which the embryo utilized a large part of its reserve lipids and sugars. 


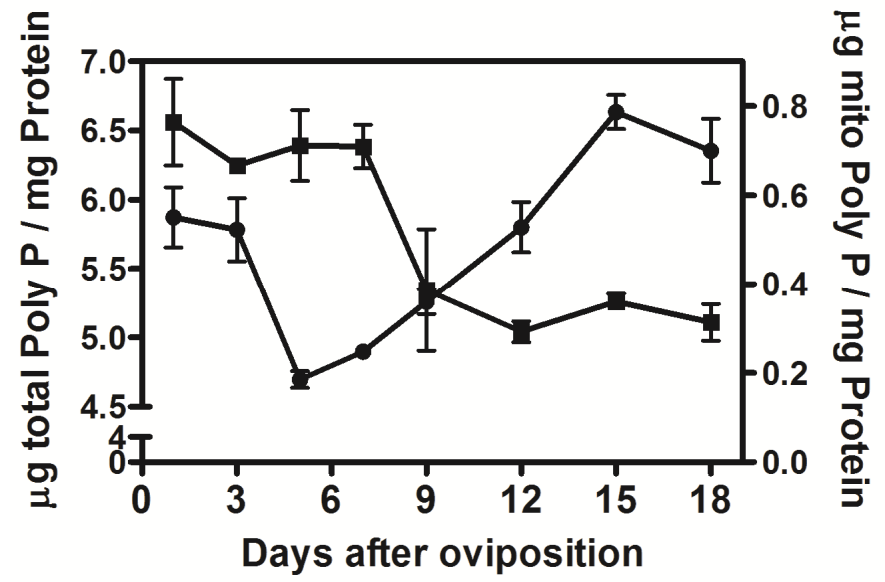

Fig. 4. Polyphosphate metabolism during R. microplus embryogenesis. Polyphosphate levels during embryogenesis in the mitochondrial fraction $(\bullet)$ and total polyphosphate $(\boldsymbol{\bullet})$ during embryogenesis. The results represent the mean \pm SD of three independent experiments, in triplicate.

\subsection{Inorganic polyphosphate metabolism in tick mitochondria}

Mitochondria from tick embryos in the segmentation stage (ninth day after oviposition) were isolated and respiration was measured using pyruvate as the substrate. The rate of oxygen consumption was $30 \mathrm{nmol} / \mathrm{min} / \mathrm{mg}$ protein, and the respiratory control ratio (RCR) was 6.5. The process was $\mathrm{KCN}$ - and oligomycin-sensitive, his fraction exhibited an ATP hydrolyses azide sensitivity, a mitochondrial marker higher than $80 \%$, and no activity of glucose-6-phosphate dehydrogenase, a cytosol marker, was detected (Table 1).

\begin{tabular}{llllll}
\hline & State 3 & State 4 & RCR & $\begin{array}{l}\text { \% F - ATPase } \\
\text { azide sensitive }\end{array}$ & $\begin{array}{l}\text { G6PDH } \\
\text { (U/mg protein) }\end{array}$ \\
\hline $\begin{array}{l}\text { Homogenate } \\
\begin{array}{l}\text { Mitochondrial } \\
\text { fraction }\end{array}\end{array}$ & --- & --- & --- & $49.50 \%$ & $2.9 \pm 0.4$ \\
\hline
\end{tabular}

Table 1. Mitochondrial characterization

Once the mitochondria were characterized, mitochondria in eggs in the segmentation stage (ninth day after ovoposition) were isolated and exopolyphosphatase activity was measured in order to evaluate the regulation of its activity. The influence of NADH, phosphate, and ADP was investigated in concentrations ranging from 0.1 to $2.0 \mathrm{mM}$. The activity of exopolyphosphatase was stimulated by a factor of two by NADH, whereas its activity was completely inhibited by $2 \mathrm{mM}$ phosphate and slightly stimulated by ADP (Figure 5A). The activity of exopolyphosphatase was also measured during mitochondrial respiration using pyruvate as the substrate and polyphosphate as the only phosphate source. During this assay, the addition of a small amounts of ADP $(0.2 \mathrm{mM})$ induced state 3 (phosphorylating respiratory rate) followed by state 4 (non-phosphorylating respiratory rate), when all of the ADP was converted to ATP. 

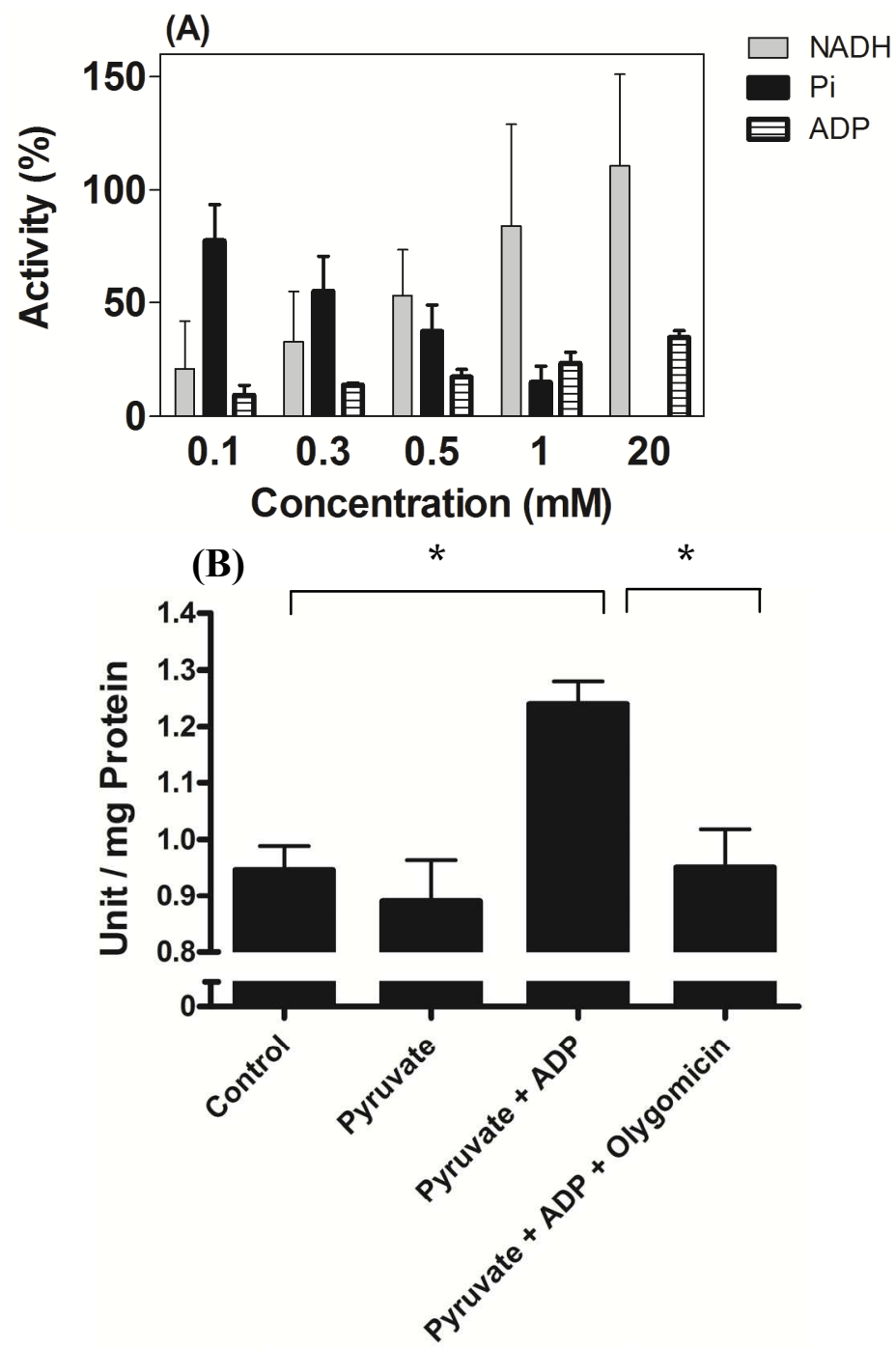

Fig. 5. In (A), Mitochondrial exopolyphosphatase activity in R. microplus embryos. Mitochondria from eggs on the ninth day of embryogenesis were isolated and exoolyphosphatase activity was determined using polyphosphate $e_{3}$ in the presence of $0.1-2$ $\mathrm{mM} N A D H, A D P$ and $\mathrm{Pi}$. The results represent the mean $\pm \mathrm{SD}$ of three independent experiments, in triplicate. B) Exopolyphosphatase activity was measured in the mitochondria of eggs on the ninth day of development during mitochondrial respiration with pyruvate as the oxidative substrate, polyphosphate 3 as the exopolyphosphatase substrate and olygomicin as ATP synthase. The activity is expressed as units per milligram of total protein and the results represent the mean \pm SD of three independent experiments, in triplicate. The asterisk $(*)$ denotes the difference between the populations and the significance was determined by a two-way ANOVA test (Kruskal-Wallis). 
Thus, during state 3, a balance existed between the release of phosphate by exopolyphosphatase and ATP synthesis, since exopolyphosphatase activity was measured by the amount of phosphate present. The exopolyphosphatase activity increased during mitochondrial respiration when pyruvate and ADP were added. This increase did not occur without the addition of ADP, indicating that exopolyphosphatase is stimulated during state 3 and that the rate of phosphate release is higher than the rate of ATP synthesis. Indeed, the stimulatory effect was antagonized by olygomicin, an ATP synthase inhibitor (Figure 5B). These data suggest that mitochondrial exopolyphosphatase activity is regulated by phosphate and the energy demand.

Furthermore, it was possible to measure ADP-dependent mitochondrial oxygen consumption in the presence of polyphosphate and in the absence of any other phosphate source. This oxygen consumption was observed using polyphosphate 3 and polyphosphate 15 ; however, the consumption was higher with polyphosphaste 3 . On the other hand, heparin, an exopolyphosphatase inhibitor, blocked oxygen consumption, which was recovered when $5 \mathrm{mM}$ phosphate was added and was again interrupted by the addition of oligomycin, an ATP-synthase inhibitor (Figure 6). These results suggest that polyphosphate was used as a phosphate donor for ATP synthesis due to the mitochondrial coupling observed when mitochondrial respiration was interrupted by oligomycin and the existence of membrane exopolyphosphatase in this process, due to the inhibition by heparin, which cannot cross the mitochondrial membrane and has its active site oriented toward the external face of the membrane. In fact, after mitochondrial subfractionation, the main exopolyphosphatase activity was recovered in the membrane fraction, supporting this hypothesis (Table 2).

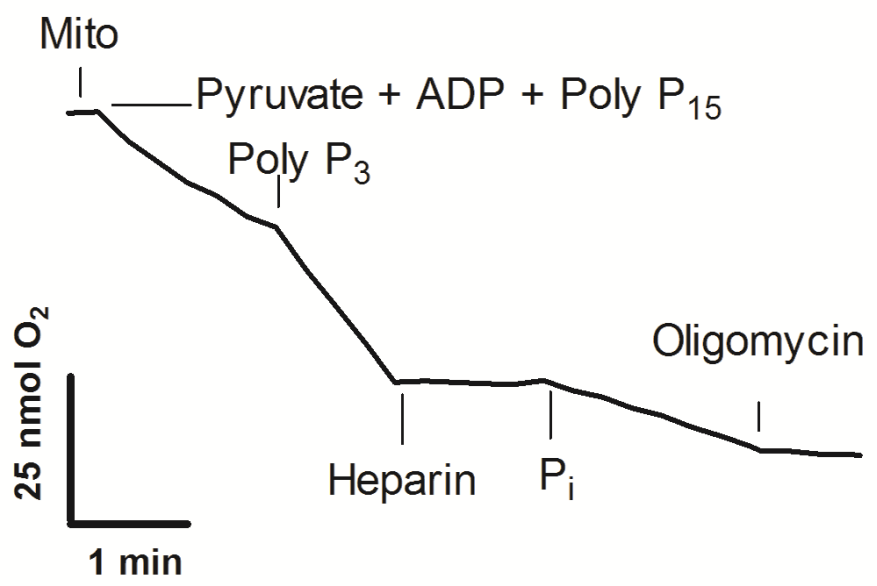

Fig. 6. Polyphosphate as a source for ATP synthesis. Oxygen consumption was monitored using a reaction buffer in the absence of a phosphate source in the eggs on the ninth day of development. The addition of $1 \mathrm{mM}$ ADP, $5 \mathrm{mM}$ pyruvate, $0.5 \mu \mathrm{M}$ polyphosphate and $_{15}, 20$ $\mu \mathrm{g} / \mathrm{mL}$ heparin, $5 \mathrm{mM}$ phosphate and $0.5 \mu \mathrm{M}$ oligomycin is represented in the figure. This experiment was repeated at least three times with different preparations, and this figure shows a representative experiment. 


\begin{tabular}{lcc}
\hline & $\begin{array}{c}\text { Exopolyphosphatase activity } \\
\text { (U / mg protein) }\end{array}$ & $\begin{array}{c}\text { Heparin } \\
\text { (\% inhibition) }\end{array}$ \\
\hline $\begin{array}{l}\text { Mitochondria } \\
\begin{array}{l}\text { Soluble fraction } \\
\text { (intermembrane space and matrix) }\end{array}\end{array}$ & $0.60 \pm 0.19$ & 98 \\
$\begin{array}{l}\text { Membrane fraction } \\
\text { (mixture of inner and outer membranes) }\end{array}$ & $0.35 \pm 0.06$ & 98 \\
\hline
\end{tabular}

Table 2. Exopolyphosphatase activity in mitochondrial preparations. Exopolyphosphatase activity was measured using eggs on the ninth day of development using polyphosphate 3 as the substrate. The activity is expressed as units per milligram of total protein and the results represent the mean \pm SD of three independent experiments, in triplicate.

\subsubsection{A mitochondrial membrane exopolyphosphatase}

Exopolyphosphatases have been found in prokaryotes and eukaryotes and, although in bacteria these enzymes mostly hydrolyze high molecular weight polyphosphates (Kumble \& Kornberg, 1996), at least some of the enzymes from Saccharomyces cerevisiae and Leishmania major are more active in hydrolyzing short chain polyphosphates, such as polyphosphate 3 (Kumble \& Kornberg, 1996; Rodrigues et al., 2002). Exopolyphosphatase from Escherichia coli requires divalent cations and $\mathrm{K}^{+}$for maximum activity, while exopolyphosphatase from yeast only requires divalent cations (Lichko et al., 2003). Membrane mitochondrial exopolyphosphatase activity from the hard tick $R$. microplus was found to be stimulated by $\mathrm{Mg}^{2+}$ and was insensitive to $\mathrm{K}^{+}$. Only a few compounds that inhibit exopolyphosphatase have been identified (Kornberg et al., 1999): treatment with molybdate (a common phosphohydrolase inhibitor) and fluoride (a pyrophosphatase inhibitor) showed that exopolyphosphatase present in the mitochondrial membrane fractions was insensitive to these compounds. However, heparin, a good inhibitor of other well-characterized exopolyphosphatases (Lichko et al., 2003), was effective in almost 100\% (Figure 7). In order to obtain an insight into membrane exopolyphosphatase kinetics, the apparent $\mathrm{Km}$ was measured using polyphosphate 3 and polyphosphate 15 as substrates and the results were expressed as the average of three independent experiments. The membrane exopolyphosphatase affinity for polyphosphate 3 was 10 times stronger than for polyphosphate $_{15}$ (Table 3). These results are in contrast with those found in a mitochondrial membrane-bound exopolyphosphatase of Saccharomyces cerevisiae, in which case the affinity was stronger for long-chain polyphosphates (Lichko et al., 1998). However, the data demonstrated that membrane exopolyphosphatase kinetics were in agreement with the oxygen consumption rate, which was much higher for polyphosphate 3 than polyphosphate 15 . These results reinforce the theory of coupling between the activity of this enzyme and mitochondrial ADP phosphorylation (Figure 8).

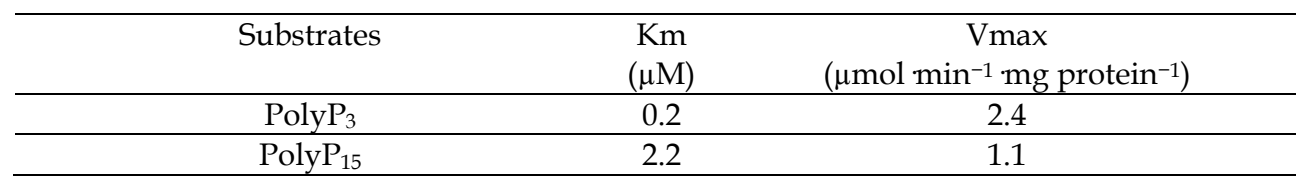

Table 3. Kinetics characterization of exopolyphosphatase activity in membrane preparations of mitochondria from $R$. microplus embryos on the ninth day of embryogenesis. 


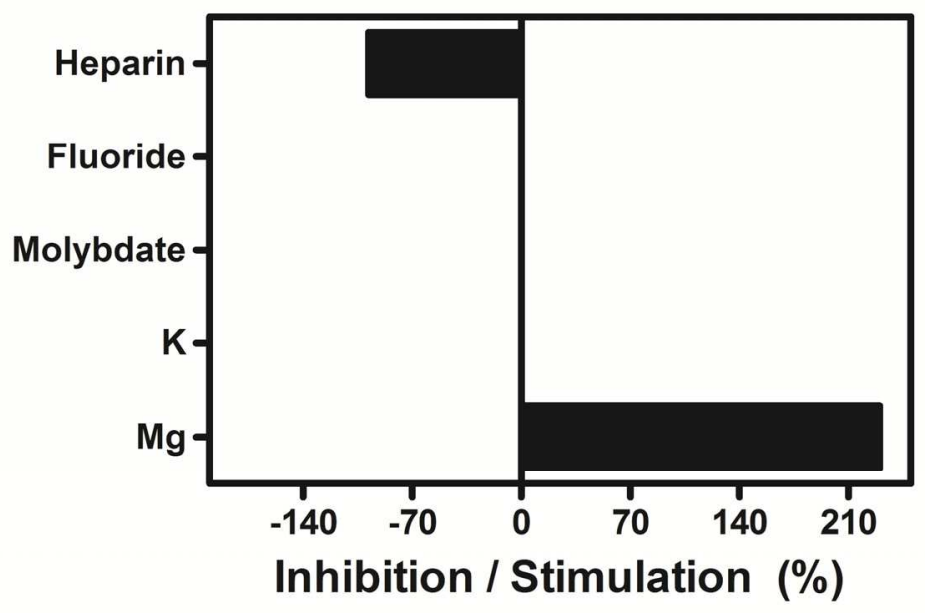

Fig. 7. The effect of some reagents on membrane exopolyphosphatase activity. Mitochondrial membrane fractions of R. microplus embryos in eggs on the ninth day of embryogenesis were isolated and the membrane exopolyphosphatase activity was determined using polyphosphate ${ }_{3}$ as the substrate in the presence of $2.5 \mathrm{mM} \mathrm{Mg}^{2+}, 50-200$ $\mathrm{mM} \mathrm{K}^{+}, 10-100 \mu \mathrm{M}$ molybdate, $1-10 \mathrm{mM} \mathrm{NaF}$ and $20 \mu \mathrm{g} / \mathrm{mL}$ heparin.

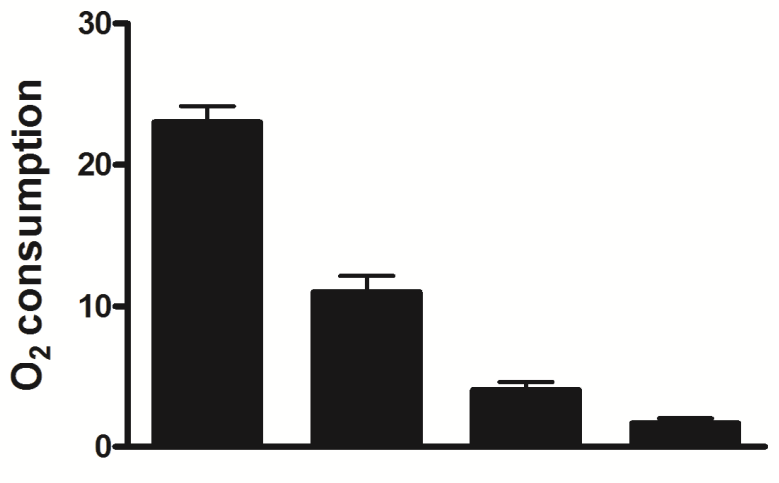

$\begin{array}{lllll}\text { Pyruvate } & + & + & + & + \\ \text { ADP }_{\operatorname{PolyP}_{3}} & + & + & - & - \\ \operatorname{polyP}_{15} & - & + & - & +\end{array}$

Fig. 8. Involvement of membrane exopolyphosphatase in mitochondrial respiration. Oxygen consumption was monitored using a reaction buffer in the absence of a phosphate source in the eggs on the ninth day of development in the presence of $1 \mathrm{mM}$ ADP, $5 \mathrm{mM}$ pyruvate, and $0.5 \mu \mathrm{M}$ polyphosphate ${ }_{3}$ and ${ }_{15}$. The results represent the mean $\pm \mathrm{SD}$ of three independent experiments, in triplicate. 
To further investigate the regulation of membrane exopolyphosphatase during mitochondrial respiration, the activity was measured using pyruvate as the substrate and polyphosphte as the only source of phosphate. Membrane exopolyphosphatase activity increased during mitochondrial respiration when pyruvate and ADP were added and the stimulatory effect was antagonized by potassium cyanide addition (decreased electron flux) and increased by protonophore carbonyl cyanide-p-trifluoromethoxyphenylhydrazone (increased electron flux), suggesting that membrane exopolyphosphatase could be modulated by the electron flux (Figure 9). These findings are consistent with those of Pavlov et al., 2010, who demonstrated that the production and consumption of mitochondrial polyphosphate depends on the activity of the oxidative phosphorylation machinery in mammalian cells. Furthermore, heparin completely inhibited exopolyphosphatase activity, reinforcing the role of membrane exopolyphosphatase during mitochondrial respiration, and the respiration activation by membrane exopolyphosphatase activity indicated that exopolyphosphatase could be close to the site of ATP production.

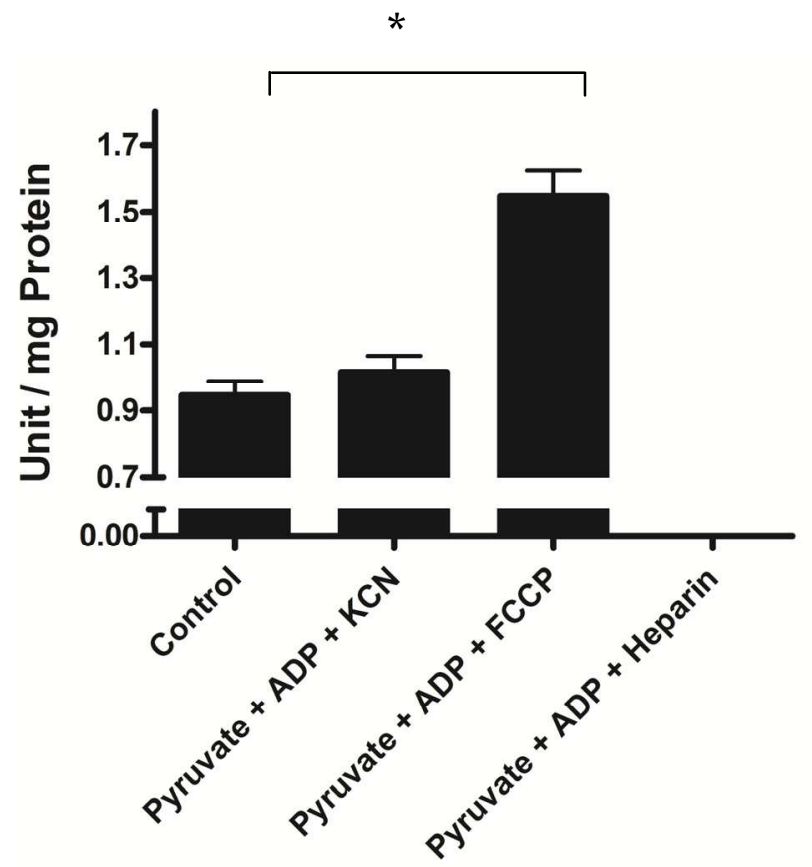

Fig. 9. Regulation of mitochondrial exopolyphosphatase activity during mitochondrial respiration. The activity of exopolyphosphatase was measured in the mitochondria of the eggs on the ninth day of development during mitochondrial respiration, using pyruvate as the oxidative substrate, polyphosphate 3 as the exopolyphosphatase substrate, $\mathrm{KCN}$ as the respiratory chain inhibitor, FCCP as the un-coupler and heparin as the exopolyphosphatase inhibitor. The activity was expressed as units per milligram of total protein and the results represent the mean \pm SD of three independent experiments, in triplicate. The asterisk $\left({ }^{*}\right)$ denotes the difference between the populations and the significance was determined by a two-way ANOVA test (Kruskal-Wallis). 
Despite the regulation of membrane exopolyphosphatase by an increased or decreased electron flux, the sensitivity of this enzyme according to the redox state using polyphosphate 3 as the substrate was evaluated. The influence of $1.0 \mathrm{mM}$ dithiothreitol (DTT) and $1.0 \mathrm{mM}$ hydrogen peroxide $\left(\mathrm{H}_{2} \mathrm{O}_{2}\right)$ was investigated at different times and the exopolyphosphatase activity was stimulated and inhibited by $50 \%$ of both, suggesting that exopolyphosphatase is tightly regulated by the redox state (Figure 10).

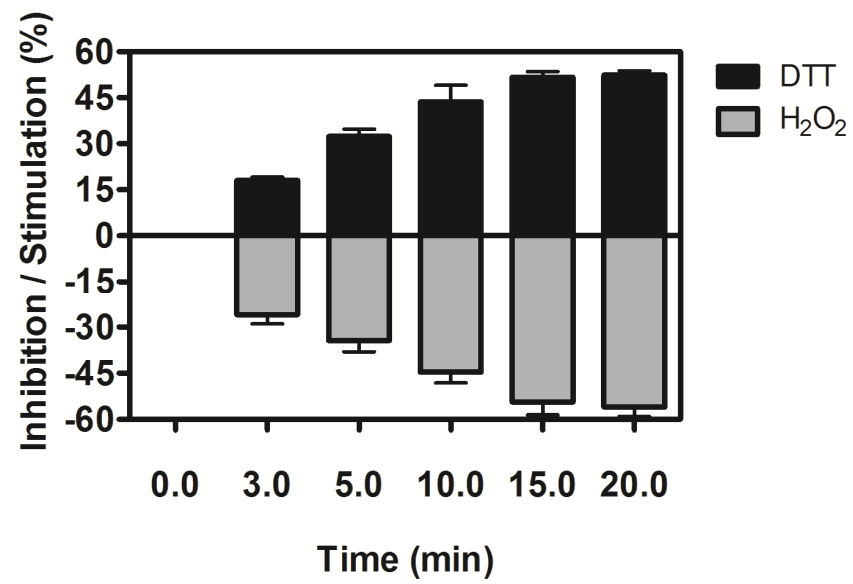

Fig. 10. The redox regulation of mitochondrial membrane exopolyphosphatase.

Exopolyphosphatase activity was measured in the mitochondria of the eggs on the ninth day of development using polyphosphate 3 as the substrate. The mitochondria were treated with $1 \mathrm{mM}$ DTT and $1 \mathrm{mM} \mathrm{H}_{2} \mathrm{O}_{2}$ for 0-20 min. The results represent the mean $\pm \mathrm{SD}$ of three independent experiments, in triplicate.

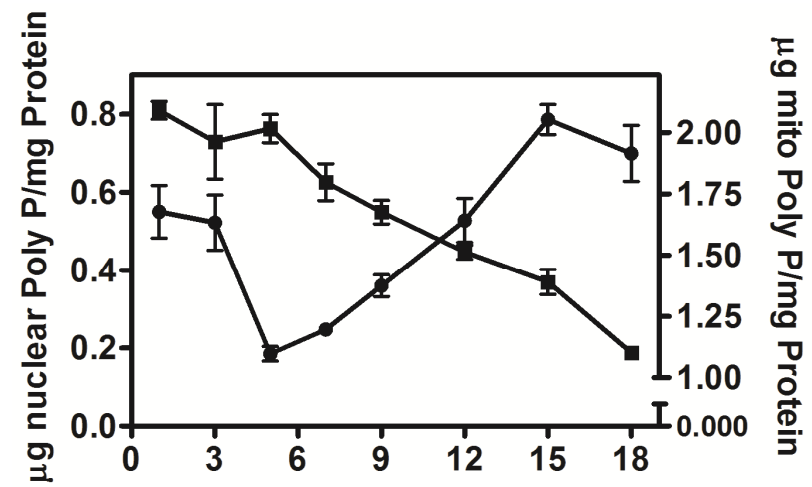

Days after oviposition

Fig. 11. Polyphosphate quantification in the nuclear and mitochondrial fractions.

Polyphosphate levels during embryogenesis in the nuclear fraction ( $\mathbf{m})$ and mitochondrial fraction $(\bullet)$ during embryogenesis. The results represent the mean \pm SD of three independent experiments, in triplicate. 
Additionally, mitochondrial polyphosphate can form polyphosphate/ $\mathrm{Ca}^{2+} / \mathrm{PHB}$ complexes (Reusch, 1989) with ion-conducting properties similar to those of the native mitochondrial permeability transition pore (Pavlov et al., 2005). Polyphosphatases localized in the membrane can not only degrade, but they can also synthesize polyphosphate inside these complexes (Lichko et al., 1998). During the embryogenesis of R. microplus, the synthesis of polyphosphate occurs in mitochondria but not in the nuclei (Figure 11). As polyphosphate kinases have only been found in prokaryotes, the observation that polyphosphate synthesis in ticks only occurs in the mitochondrial fraction supports the possibility that such synthesis probably occurs via the action of these complexes, as already suggested for other organisms (Reusch and Sadoff, 1988; Lichko et al., 1998; Reusch et al., 1998; Abramov et al., 2007).

\section{Conclusion}

The ubiquity of polyphosphate and the variation in its chain length, location and metabolism indicate the relevant functions of this polymer, including those in animal systems. The present study showed that electron flux and the redox state may exert some influence on and be influenced by the activity of membrane exopolyphosphatase, and its describes a role for polyphosphate in the energy supply and ATP synthesis during embryogenesis of the hard tick $R$. microplus. In this sense, a more comprehensive understanding of polyphosphate biochemistry during tick embryo development may unravel additional targets that could be effective in the control of this ectoparasite and shed new light on polyphosphate metabolism.

\section{Acknowledgment}

This work was supported by grants from Fundação de Amparo à Pesquisa do Estado do Rio de Janeiro-FAPERJ, Conselho Nacional de Desenvolvimento Científico e TecnológicoCNPq, Programa de Núcleos de Excelência-PRONEX, Programa Nacional de Cooperação Acadêmica-PROCAD-CAPES, Instituto Nacional de Ciência e Tecnologia/Entomologia Molecular-INCT/EM and FUNEMAC.

\section{References}

Abramov, A. Y., Fraley, C., Diao, C. T., Winkfein, R., Colicos, M. A., Duchen, M. R., French, R. J. \& Pavlov, E. (2007). Targeted polyphosphatase expression alters mitochondrial metabolism and inhibits calcium-dependent cell death. Proceedings of the National Academy of Sciences. Vol.104, (November, 2007), pp. 18091-18096, ISSN 0027-8424

Bate, M. \& Arias, A, M. (1991). The embryonic origin of imaginal discs in Drosophila. Development, Vol.112, (July, 1991), pp. 755-761, ISSN 0950-1991

Bligh, E. G. \& Dyer, W. J. (1959). A rapid method of total lipid extraction and purification. Canadian Journal of Biochemistry and Physiology, Vol.37, (August, 1959), pp. 911-917, ISSN 0576-5544

Campos, E., Moraes, J., Facanha, A, R., Moreira, E., Valle, D., Abreu, L., Manso, P, P., Nascimento, A., Pelajo-Machado, M., Lenzi, H., Masuda, A., Vaz Ida S Jr. \& Logullo, C. (2006). Kinetics of energy source utilization in Boophilus microplus (Canestrini, 1887) (Acari: Ixodidae) embryonic development. Veterinary Parasitology, Vol.138, (February, 2006), pp. 349-357, ISSN 0304-4017 
Clements, A., Bursa, D., Gatsos, X., Perry, A, J., Civciristov, S., Celik, N.,Likic, V, A., Poggio, S., Jacobs-Wagner, C., Strugnell, R, A. \& Trevor Lithgow, T. (2009). The reducible complexity of a mitochondrial molecular machine. Proceedings of the National Academy of Sciences, Vol.106, (September 2009), pp. 15791-15795, ISSN 0027-8424

Dubois, M., Gilles, K. A., Hamilton, J. K., Rebers, P. A. \& Smith, F. (1956). Calorimetricmethod for determination of sugar and related substances. Analytical Chemistry, Vol.25, (March, 1956), pp. 350-356, ISSN 0003-2700

Fagotto, F. (1990). Yolk degradation in tick eggs: I. Occurrence of a cathepsin L-like acid proteinase in yolk spheres. Archives of Insect Biochemistry and Physiology, Vol.14, (February, 1990), pp. 217-235, ISSN 0739-4462

Guerrero, F, D., Nene, V, M., George, J, E., Barker, S, C. \& Willadsen, P. (2006). Sequencing a new target genome: the Boophilus microplus (Acari: Ixodidae) genome project. Journal of Medical Entomology, Vol.43, (January, 2006), pp. 9-16, ISSN 0022-2585

Jones, H, E., Holland, I, B., Jacq, I, B., Wall, T. \& Campbell, A.K. (2003). Escherichia coli lacking the AcrAB multidrug efflux pump also lacks nonproteinaceous, PHBpolyphosphate $\mathrm{Ca}^{2+}$ channels in the membrane. Biochimica et Biophysica Acta Biomembranes, Vol. 1612, pp. 90-97, ISSN 0005-2736

Kim, K, S., Rao, N, N., Fraley, C, D. \& Kornberg, A. (2002). Inorganic polyphosphate is essential for long-term survival and virulence factors in Shigella and Salmonella spp. Proceedings of the National Academy of Sciences, Vol.99, (May 2002), pp. 76757680, ISSN 0027-8424

Kornberg, A. (1995). Inorganic polyphosphate: toward making a forgotten polymer unforgettable. Journal of Bacteriology, Vol.177, (February, 1995), pp. 491-496, ISSN 0021-9193

Kornberg, A., Rao, N, N. \& ult-Riche, D. (1999). Inorganic polyphosphate: a molecule of many functions. Annual Review of Biochemistry, Vol. 68, (July 1999), pp. 89-125, ISSN 0066-4154

Kulaev, I, S. \& Vagabov, V, M. (1983). Polyphosphate metabolism in micro-organisms. Advances in Microbiol Physiology, Vol.24, pp. 83-171, ISSN 0065-2911

Kulaev, I. \& Kulakovskaya, T. (2000). Polyphosphate and phosphate pump. Annual Review of Microbiology, Vol. 54, (October 2000), pp. 709-734, ISSN 0066-4227

Kulaev, I, S.; Vagabov, V, M. \& Kulakovskaya, T, V. (2004). The Biochemistry of Inorganic Polyphosphate, Wiley, ISBN 047085810 9, Chichester, England

Kulakovskaya, T, V., Lichko, L, P., Vagabov, V, M., \& Kulaev, I, S. (2010). Inorganic Polyphosphates in Mitochondria. Biochemistry (Moscow), Vol.75, (July 2010), pp. 825-831, ISSN 0006-2979

Kumble, K. D. \& Kornberg, A. (1996). Endopolyphosphatases for long chain inorganic polyphosphate in yeast and mammals. Journal of Biological Chemistry, Vol.271, (October, 1996), pp. 27146-27151, ISSN 0021-9258

Kuroda, A., Nomura, K., Ohtomo, R., Kato, J., Ikeda, T., Takiguchi, N., Ohtake, H. \& Kornberg, A. (2001). Role of inorganic polyphosphate in promoting ribosomal protein degradation by the Lon protease in E. coli. Science, Vol. 293, (July 2001), pp. 705-708, ISSN 0036-8075

Lichko, L. P., Andreeva, N. A., Kulakovskaya, T. V. \& Kulaev, I. S. (2003). Exopolyphosphatases of the yeast Saccharomyces cerevisiae. FEMS Yeast Research, Vol.3, (January, 2003), pp. 233-238, ISSN 1567-1356 
Lichko, L. P., Kulakovskaya, T. V. \& Kulaev, I. S. (1998). Membrane-bound and soluble polyphosphatases of mitochondria of Saccharomyces cerevisiae: identification and comparative characterization. Biochimica et Biophysica Acta - Biomembranes, Vol.1372, (January, 1998), pp. 153-162. ISSN 0005-2736

McInerney, P., Mizutani, T. \& Shiba, T. (2006). Inorganic polyphosphate interacts with ribosomes and promotes translation fidelity in vitro and in vivo. Molecular Microbiology, Vol.60, (April 2006), pp. 438-447, ISSN 0950-382X

Monnerat, A, T., Machado, M, P., Vale, B, S., Soares, M, J., Lima, J, B., Lenzi, H, L. \& Valle, D. (2002). Anopheles albitarsis embryogenesis: morphological identification of major events. Memorias do Instiuto Oswaldo Cruz, Vol.97. (June, 2002), pp. 589-596, ISSN 0074-0276

Negoda, A., Negoda, E., Xian, M. \& Reusch, R.N. (2009). Role of polyphosphate in regulation of the Streptomyces lividans KcsA channel. Biochimica et Biophysica Acta, Vol.1788, (March 2009) pp. 608-614, ISSN 0006-3002

Nusslein-Volhard, C. \& Roth, S. (1989). Axis determination in insect embryos. Ciba Foundation Symposium, Vol.144, pp. 37-55, ISBN: 9780471923060

Pavlov, E., Aschar-Sobbi, R., Campanella, M., Turner, R. J., Gómes-García, M. \& Abramov, A. Y. (2010). Inorganic polyphosphate and energy metabolism in mammalian cells. Journal of Biological Chemistry. Vol.285, (March, 2010), pp. 9420-9428, ISSN 0021-9258

Pavlov, E., Zakharian, E., Bladen, C., Diao, C. T. M., Grimbly, C., Reusch, R. N. \& French, R. J. (2005). A large, voltage-dependent channel, isolated from mitochondria by waterfree chloroform extraction. Biophysical Journal. Vol.88, (April, 2005), pp. 2614-2625, ISSN 0006-3495

Rashid, M, H., Rumbaugh, K., Passador, L., Davies, D, G., Hamood, A, N., Iglewski, B, H. \& Kornberg, A. (2000). Polyphosphate kinase is essential for biofilm development, quorum sensing, and virulence of Pseudomonas aeruginosa. Proceedings of the National Academy of Sciences, Vol.97, (August 2000), pp. 9636-9641, ISSN 0027-8424

Reusch, N. M. \& Sadoff, H. L. (1988). Putative structure and functions of a poly-betahydroxybutyrate/ calcium polyphosphate channel in bacterial plasma membranes. Proceedings of the National Academy of Sciences. Vol.85, (June, 1988), pp. 4176-4180, ISSN 0027-8424

Reusch, R, N. (1989). Poly-beta-hydroxybutyrate/calcium polyphosphate complexes in eukaryotic membranes. Proceedings of the Society for Experimental Biology and Medicine, Vol. 191, (September 1989), pp. 377-381, ISSN 1525-1373

Rodrigues, C. O., Ruiz, F. A., Vieira, M., Hill, J. E. \& Docampo, R. (2002). An acidocalcisomal exopolyphosphatase from Leishmania major with high affinity for short chain polyphosphate. Journal of Biological Chemistry, Vol.277, (October, 2002), pp. 5089950906, ISSN 0021-9258

Silveira, A, B., Castro-Santos, J., Senna, R., Logullo, C., Fialho, E. \& Silva-Neto, M, A. (2006). Tick vitellin is dephosphorylated by a protein tyrosine phosphatase during egg development: effect of dephosphorylation on VT proteolysis. Insect Biochemistry and Molecular Biology, Vol.36, (March, 2006), pp. 200-209, ISSN 0965-1748

Sonenshine, D, E., Kocan, K, M. \& de la, F, J. (2006). Tick control: further thoughts on a research agenda. Trends in Parasitology, Vol.22, (September, 2006), pp. 550-551, ISSN $1471-4922$ 


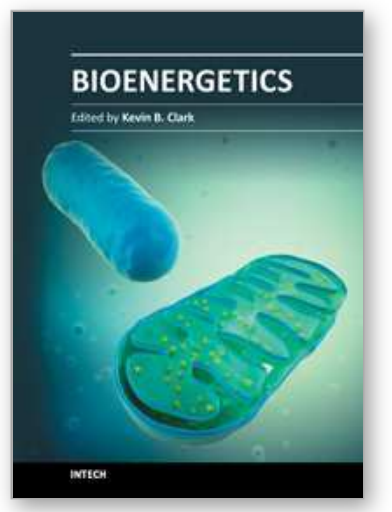

\author{
Bioenergetics \\ Edited by Dr Kevin Clark
}

ISBN 978-953-51-0090-4

Hard cover, 272 pages

Publisher InTech

Published online 02, March, 2012

Published in print edition March, 2012

Cellular life depends upon energy storage, transformation, utilization, and exchange in order to optimally function and to stay-off death. The over 200-year-old study of how cells transform biological fuels into usable energy, a process broadly known as bioenergetics, has produced celebrated traditions in explaining origins of life, metabolism, ecological adaptation, homeostasis, biosynthesis, aging, disease, and numerous other life processes. InTech's edited volume, Bioenergetics, brings together some of these traditions for readers through a collection of chapters written by international authorities. Novice and expert will find this book bridges scientific revolutions in organismic biology, membrane physiology, and molecular biology to advance the discipline of bioenergetics toward solving contemporary and future problems in metabolic diseases, life transitions and longevity, and performance optimization.

\title{
How to reference
}

In order to correctly reference this scholarly work, feel free to copy and paste the following:

Eldo Campos, Arnoldo R. Façanha, Jorge Moraes and Carlos Logullo (2012). Role of Inorganic Polyphosphate in the Energy Metabolism of Ticks, Bioenergetics, Dr Kevin Clark (Ed.), ISBN: 978-953-51-0090-4, InTech, Available from: http://www.intechopen.com/books/bioenergetics/role-of-inorganic-polyphosphate-in-theenergy-metabolism-of-ticks

\section{INTECH}

open science | open minds

\author{
InTech Europe \\ University Campus STeP Ri \\ Slavka Krautzeka 83/A \\ 51000 Rijeka, Croatia \\ Phone: +385 (51) 770447 \\ Fax: +385 (51) 686166 \\ www.intechopen.com
}

\author{
InTech China \\ Unit 405, Office Block, Hotel Equatorial Shanghai \\ No.65, Yan An Road (West), Shanghai, 200040, China \\ 中国上海市延安西路65号上海国际贵都大饭店办公楼405单元 \\ Phone: +86-21-62489820 \\ Fax: +86-21-62489821
}


(C) 2012 The Author(s). Licensee IntechOpen. This is an open access article distributed under the terms of the Creative Commons Attribution 3.0 License, which permits unrestricted use, distribution, and reproduction in any medium, provided the original work is properly cited. 